\title{
Investigation of crack propagation resistance of 304L, 316L and 316L(N) austenitic steels in liquid sodium
}

\author{
B. Barkia ${ }^{\text {a, }}{ }^{3}$, J.L. Courouau ${ }^{\text {b }}$, E. Perrin ${ }^{\text {a }}$, V. Lorentz ${ }^{\text {b }}$, M. Rivollier ${ }^{\text {b, }}{ }^{2}$, R. Robin ${ }^{\text { }}$, L. Nicolas ${ }^{\text {, }}$, \\ C. Cabet ${ }^{\mathrm{d}}$, T. Auger ${ }^{\mathrm{a}, *, 1}$ \\ ${ }^{a}$ MSSMAT, CentraleSupélec, UMR CNRS 8579, Université Paris-Saclay, Grande voie des vignes, 92295, Chatenay-Malabry, France \\ b Den-Service de la Corrosion et du Comportement des matériaux dans leur Environnement (SCCME), CEA, Université Paris-Saclay, F-91191, Gif-sur-Yvette, \\ France \\ ' CEA, DEN, Département des matériaux Nucléaires (DMN), CEA, Université Paris-Saclay, F-91191, Gif-sur-Yvette, France \\ d CEA, DEN, Service de Recherches de Métallurgie Physique, Université Paris-Saclay, F-91191, Gif-sur-Yvette, France
}

\section{H I G H L I G H T S}

- The fracture behavior of 3 austenitic steels has been tested in liquid sodium on notched tensile specimens after pre-wetting in oxygenated sodium (200 wppm).

- Austenitic steels are shown to have decreasing crack propagation resistance in liquid oxygenated sodium for some experimental conditions.

- Crack initiation occurs after significant plastic deformation.

- Evidences of brittle fracture are observed on the fracture surface.

- The effect of impurities on LME susceptibility is estimated to be unlikely.

Keywords:

Austenitic stainless steel

Sodium

Fracture

\begin{abstract}
A B S T R A C T
In order to assess the susceptibility of candidate structural materials to Liquid Metal Embrittlement (LME), the fracture behavior of three grades of austenitic steels was investigated in oxygenated (200 wppm) liquid sodium in the temperature range [473-673 K] on notched axisymmetric tensile specimens. The tests were carried out in an inert glove box at very low concentrations of dioxygen and humidity $(<1 \mathrm{ppm})$ to prevent further contamination after pre-exposure in oxygenated liquid sodium. A decrease in crack propagation resistance of the three austenitic steels ( $304 \mathrm{~L}, 316 \mathrm{~L}(\mathrm{~N}), 316 \mathrm{~L}$ ) is observed in oxygenated liquid sodium (200 wppm) from 573, 623 and $673 \mathrm{~K}$ respectively after pre-wetting in oxygenated sodium. This reduction is correlated with a ductile to brittle change of the fracture surface. This effect observed with the three austenitic steels is attributed to the onset of LME after significant plastic deformation.
\end{abstract}

\footnotetext{
* Corresponding author. MSSMAT, CentraleSupélec, UMR CNRS 8579, Université Paris-Saclay, Grande voie des vignes, 92295, Chatenay-Malabry, France.

E-mail address: thierry.auger@ensam.eu (T. Auger).

1 Present address, PIMM/ENSAM-CNRS-CNAM, UMR 8006, 151 Bld de l'hôpital 75013 Paris, France.

2 Present address, CentraleSupélec, Université Paris-Saclay, Laboratoire de Génie des Procédés et Matériaux, 3 rue Joliot Curie, 91190 Gif-sur-Yvette, France.

3 Present address, Den-Service d'Etudes Analytiques et de Réactivité des Surfaces (SEARS), CEA, Université Paris-Saclay, F-91191, Gif-sur-Yvette, France.
}

\section{Introduction}

Liquid sodium has a range of potential applications such as coolant medium in nuclear reactor or solar thermal power plants. The issue of sodium interaction with structural materials has been an important topic of investigation since the early days of its use. The alloying elements of structural materials dissolve in ultrapure liquid sodium leading to subsequent mass transfer in the presence of temperature gradients and high flow conditions. In addition, the long-term evolution of material crucially depends on its interaction with the dissolved oxygen content. Indeed, it is known that dissolution kinetics are enhanced by traces of oxygen. Corrosion in liquid 
sodium is then mitigated via an active control of the oxygen concentration below a few wppm [1]. Carbon transport processes between structural materials or parts of sodium loops lead to carburization/decarburization issues [2]. Therefore, long term effects of exposure in loops have been predominantly studied in terms of material microstructure evolution and the subsequent mechanical properties degradation [3]. The question of a possible sensitivity to liquid metal embrittlement (LME) of austenitic steels in liquid sodium is also of interest although such a case has never been reported to our knowledge on a component of an operating facility. While several LME cases in liquid sodium were observed on ferritic or martensitic steels through sensitivity tests carried out in laboratory's conditions [4,5], the effect of sodium on the fracture mode of austenitic steels is regarded as negligible [6,7]. This stems from results of tensile testing carried out ex-situ after pre-exposure in vacuum test vessels. These tests, although extremely demanding due to the long-term pre-exposure required, were not carried out in a liquid sodium environment, as already mentioned, and were only targeting the detrimental effects on steel's microstructure of long term high temperature liquid sodium exposure. On the other hand, while the effect of sodium on 304 steel fatigue crack behavior was shown to be negligible at $823 \mathrm{~K}$ [8], intergranular cracking of the 304 austenitic steel was also observed during tertiary creep in sodium at the same temperature [9]. Similar behavior was also reported in sodium contaminated by sodium hydroxide [10]. Overall, the effect of sodium on the fracture mode seems to have a different outcome when sensitivity tests are carried out in-situ. Indeed, the $304 \mathrm{~L}$ austenitic steel was later on found to have an interfacial LME fracture mode in liquid sodium at lower temperature (between $473 \mathrm{~K}$ and $673 \mathrm{~K})[11,12]$.

It is not sufficient to carry out in-situ experiments, one has also to make sure that LME prerequisites are fulfilled. Indeed, in a recent study of LME sensitivity on austenitic steels (15-15Ti and $316 \mathrm{~L}(\mathrm{~N})$ ) by in-situ small punch tests (SPT), a small effect of sodium on mechanical resistance was found for these steels, associated mainly with a ductile fracture mode [13]. Some scatter as a function of strain rate and temperature was also observed in these data. It is to be recalled that sodium doesn't wet native steel's oxides during short time exposure [14] while this is a requirement to correctly induce crack initiation in LME. This scatter might be attributed to the somewhat ineffective wetting procedure inducing uncertainty about the actual wettability state of the specimen during these tests. This stresses out the importance of carrying out mechanical tests in well-controlled conditions notably good wetting for example obtained by pre-exposure in oxygenated sodium [15].

The present study investigated the LME susceptibility in liquid sodium of three austenitic steels, $304 \mathrm{~L}, 316 \mathrm{~L}$ and $316 \mathrm{~L}(\mathrm{~N})$ in welldefined wetting and static flow conditions (i.e using the recent insight obtained by the analysis of wetting by pre-exposure to liquid oxygenated sodium) to enable reproducible crack initiation independent of the inherent fluctuations of short term corrosion kinetics. After the wetting procedure, the residual sodium on the sample has to be prevented from contamination. Indeed, the role of minute amount of impurities in the gas gathered by the highly reactive liquid sodium can also be a source of unwanted contamination. Water vapor is a main concern because of its tendency to strongly react with sodium to form sodium hydroxide. In the absence of di-oxygen and di-hydrogen in the gas phase, the contamination by sodium hydroxide decomposes upon raising the temperature, thereby releasing hydrogen and oxygen in sodium [10]. High purity of the test and handling environment is therefore required to avoid such effects. In order to isolate the liquid sodium of such potential contamination by gas phase, we developed a new experimental setup able to fully isolate the specimens wetted with liquid sodium from contact with water vapor as well as di-oxygen during transfer and mechanical loading. The LME susceptibility of the three steels was investigated as a function of temperature from $373 \mathrm{~K}$ up to $673 \mathrm{~K}$.

\section{Materials and experiments}

\subsection{Description of the testing devices}

In mechanical testing experiments, one usually does not have the capability to wait for the required time to dissolve the native oxide even if the sodium chemistry is in the reducing range (typically $[0]<3 \mathrm{wppm}$ for nuclear reactor [2]) with the exception of creep testing which is a long-term mechanical test carried out in dedicated loops. With other types of mechanical testing, specimens need to be prepared in a pre-wetted state to allow reproducible crack initiation conditions followed by sodium supply at the crack tip by capillarity during the crack propagation phase. In a previous work [5], the key step was the realization that one can induce sodium to wet the surface via the buildup of a ternary oxide in oxygenated sodium $\left(\mathrm{Na}_{\mathrm{x}} \mathrm{CrO}_{2}, \mathrm{x} \leq 1\right)$. This change of the sodium chemistry leads in a few tens of hour to a very reproducible wetting state via a process of reactive wetting [15]. Therefore, the experimental procedure is divided into three steps: pre-wetting in liquid oxygenated sodium, transfer under inert conditions and mechanical testing in liquid sodium in a dedicated testing apparatus.

The pre-wetting equipment is an inert glove box equipped with a sodium static pot able to reach high temperature while remaining perfectly tight. The cover gas is Ar with a continuous recycling in a purification bypass able to lower the concentration of dioxygen and water content to less than $1 \mathrm{ppm}$, which is necessary to limit contamination during handling and preparation of the test. This experimental apparatus is further described in Refs. $[5,16]$. In order to provide the same conditions during subsequent handling and testing, an argon inert glove box was designed and adapted to a MTS 20/M uniaxial electromechanical testing machine (Fig. 1a). The load line is coupled to the glove box by flexible bellows ensuring gas tightness. The glove box gas is argon and an online purification process allows to keep dioxygen and water vapor contents lower than $1 \mathrm{ppm}$. The measured humidity dew point inside the glove box is constantly lower than $-80^{\circ} \mathrm{C}$ (equivalent to less than $1 \mathrm{ppm}$ of water vapor). The overall height of the glove box is $0.8 \mathrm{~m}$ leaving ample space for the load line and several monitoring equipment. The load line has a special design to ensure electrical insulation from the glove box and heating is produced via a low voltage high intensity current (Fig. 1b). A control loop using an optical pyrometer measurement in the glove box regulates the temperature.

\subsection{Materials and experimental procedures}

In this work, three grades of austenitic stainless steel have been investigated, namely AISI $304 \mathrm{~L}, 316 \mathrm{~L}$ and $316 \mathrm{~L}(\mathrm{~N})$. Their chemical compositions are listed in Table 1. EBSD mapping analysis of the initial microstructures revealed that the three materials have weak crystallographic texture and equiaxed grains in the RollingTransverse Direction (RD-TD) plane. The average grain sizes are estimated at 25, 30 and $130 \mu \mathrm{m}$ for $304 \mathrm{~L}, 316 \mathrm{~L}$ and $316 \mathrm{~L}(\mathrm{~N})$ steel respectively ( $\Sigma 3$ annealing twins excluded). Transmission Electron Microscopy (TEM) analysis of the as received materials reveals a low density of initial dislocations typical of an annealed microstructure. An example of EBSD map and TEM characterization for $316 \mathrm{~L}(\mathrm{~N})$ grade is given in Fig. 2.

Axisymmetric notched specimens with a $4 \mathrm{~mm}$ diameter and a $15 \mathrm{~mm}$ gauge length were machined from 10,15 and $30 \mathrm{~mm}$-thick plates of $304 \mathrm{~L}, 316 \mathrm{~L}$ and $316 \mathrm{~L}(\mathrm{~N})$ respectively. The sampling 

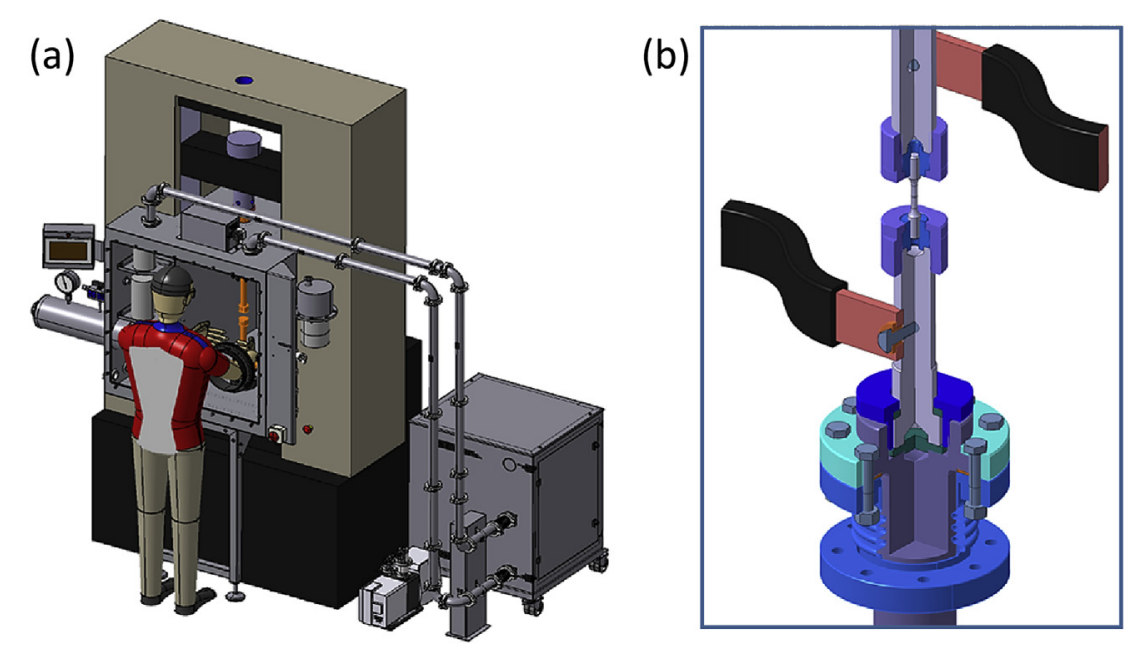

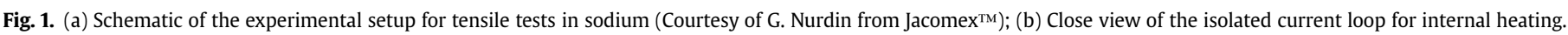

Table 1

Chemical composition (wt. \%) of the as received materials.

\begin{tabular}{|c|c|c|c|c|c|c|c|c|c|c|}
\hline \multirow[t]{2}{*}{ Temperature (K) } & \multirow[t]{2}{*}{ Crosshead displacement rate $\left(\mathrm{m} . \mathrm{s}^{-1}\right)$} & \multicolumn{3}{|l|}{$304 \mathrm{~L}$} & \multicolumn{3}{|l|}{$316 \mathrm{~L}$} & \multicolumn{3}{|l|}{$316 \mathrm{~L}(\mathrm{~N})$} \\
\hline & & Fracture mode & $\mathrm{R}_{\mathrm{E}}$ & LME & Fracture mode & $\mathrm{R}_{\mathrm{E}}$ & LME & Fracture mode & $\mathrm{R}_{\mathrm{E}}$ & LME \\
\hline 473 & $4.16 \times 10^{-8}$ & Ductile & 1.00 & No & Ductile & 0.98 & No & Ductile & 1.06 & No \\
\hline 523 & $4.16 \times 10^{-7}$ & Ductile & 1.00 & No & Ductile & 1.02 & No & Ductile & 1.00 & No \\
\hline 573 & $4.16 \times 10^{-7}$ & Brittle & 0.93 & Yes & Ductile & 1.01 & No & Ductile & 0.94 & No \\
\hline 623 & $8.33 \times 10^{-6}$ & Brittle & 0.86 & Yes & Ductile & 0.99 & No & Brittle & 0.72 & Yes \\
\hline 673 & $1.66 \times 10^{-6}$ & Brittle & 0.87 & Yes & Brittle & 0.84 & Yes & Brittle & 0.80 & Yes \\
\hline
\end{tabular}

(a)

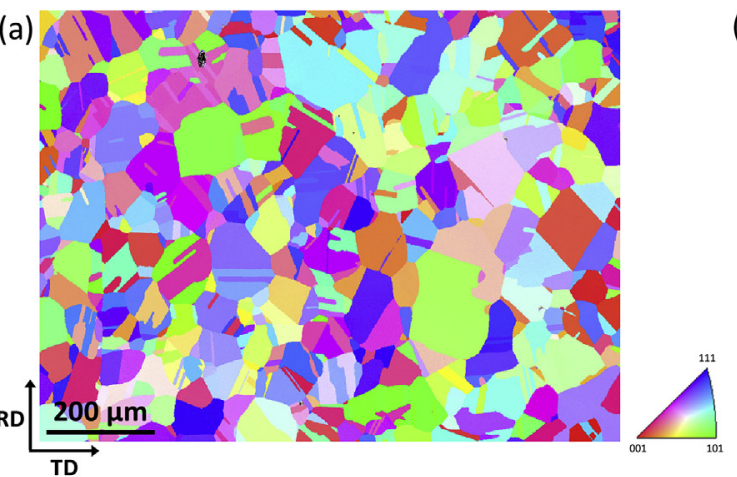

(b)

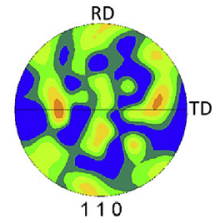

$\mathrm{RD}$

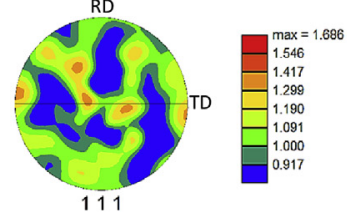

(c)

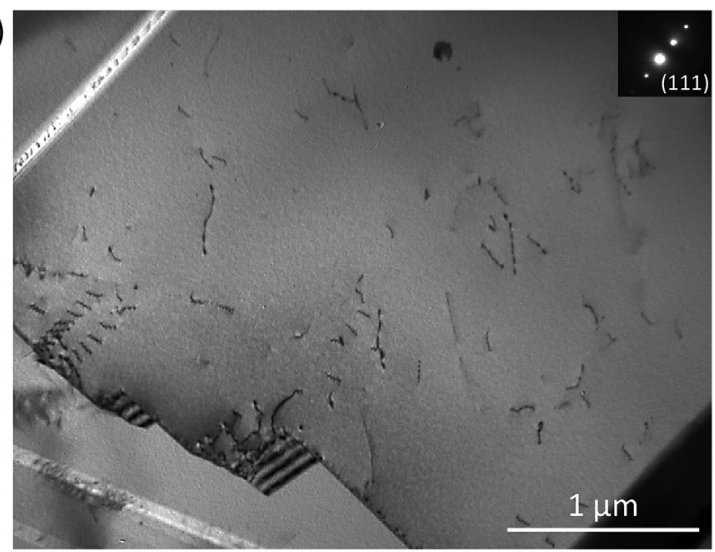

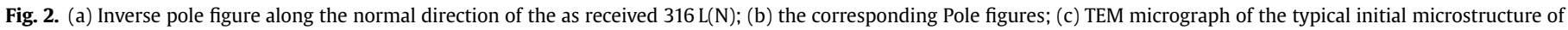
$316 \mathrm{~L}(\mathrm{~N})$.

direction was RD. A notch of $600 \mu \mathrm{m}$ depth was machined with a tip radius of $100 \pm 5 \mu \mathrm{m}$ (see Fig. 3 ).

The notched specimens were first exposed in static sodium for $250 \mathrm{~h}$ at $823 \mathrm{~K}$ for pre-wetting. The oxygen content of the sodium bath was high in order to promote wetting $\left(200 \mu \mathrm{g} \mathrm{g}^{-1}\right.$ using $\mathrm{Na}_{2} \mathrm{O}$ oxide addition after a high temperature purification step with $\mathrm{Zr}$ foils to reduce any residual oxygen in the sodium after its first melting). During pre-exposure, a thin $\mathrm{Na}_{\mathrm{x}} \mathrm{CrO}_{2}(\mathrm{x} \leq 1)$ oxide is built in-situ at the solid-liquid interface [15]. The wetting by sodium of such an oxide is typical of the reactive wetting type. This allows to completely fill the notch with a sodium layer where the wetting film reaches even its tip. The samples were then extracted from the sodium bath and the excess sodium was removed from the grips. The samples were then stored in a tight double wall inert gas transfer box and transferred to the testing glove box being fully protected from any contaminant from atmosphere during the operation. A liquid sodium bath located inside the glove box also helps trap any residual impurities from the gas surrounding the test setup. 

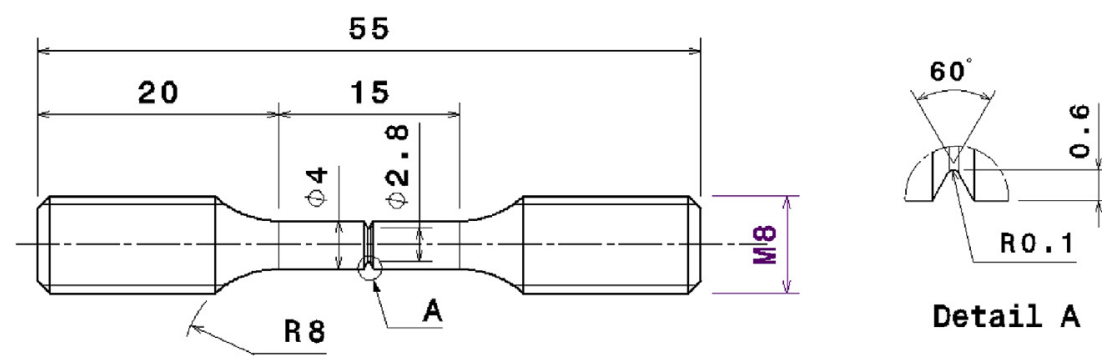

Fig. 3. Sketch of the axisymmetric notched tensile specimen.

Once mounted on the load line, the sample is heated to the requested temperature and an equilibration time at low constant load $(200 \mathrm{~N})$ is applied until thermal equilibrium of the load setup is reached. The mechanical test is then started at constant crosshead speed until fracture. The temperature of the test sample is double checked at the notch location using a type $\mathrm{K}$ thermocouple. Upon fracture, the drop of heating current is automatically detected and power is shut down. This allows slow strain rate tests lasting up to several days.

Mechanical tests were run in the temperature range from $473 \mathrm{~K}$ to $673 \mathrm{~K}$ by steps of $50 \mathrm{~K}$ and the imposed cross-head displacement rates varied from $4.16 \times 10^{-8}$ to $1.66 \times 10^{-6} \mathrm{~m} \mathrm{~s}^{-1}$. The choice of the cross-head displacement rate was limited by the test temperature. Indeed, the limited amount of sodium at the notch can eventually dry out before the end of the experiment, especially starting from $573 \mathrm{~K}$ (the vapor pressure of sodium becomes quite high $>10^{-2}$ mbar). Therefore, the cross-head displacement rate was adjusted to avoid complete sodium evaporation before the end of the mechanical test. The actual oxygen concentration in sodium is higher than the saturation limit for temperature below $618 \mathrm{~K}$ according to the Noden relation [1] (200 wppm - pre-exposure concentration) and close to the saturation limit for higher temperatures (small remaining traces of contaminants present in argon should be sufficient to reach the saturation level). In any case, the droplet remains shiny during the test indicating no large oversaturation thanked to the high purity of the glove box.

After rupture, the residual sodium remaining on the fracture surfaces was dissolved in absolute ethanol and the fracture surfaces of the specimens were analyzed using a FEI HELIOS Nanolab 650 scanning electron microscope. For each sample tested in sodium, a reference test has been performed in high purity argon. Reference specimens were also pre-exposed to sodium in the same conditions but they were tested after the dissolution of sodium residue in absolute ethanol.

\section{Results}

The influence of liquid sodium on the mechanical behavior of the 3 grades of austenitic steels is determined by first comparing the load-displacement curves and then the fracture surface with those of the reference tests performed in argon. Given the fact that the notch induces severe loading state localized at the middle of the specimen, one cannot analyze the data with the standard tensile tests criteria. To qualify a liquid metal embrittlement case in this geometry, the data require two criteria to be simultaneously fulfilled: a reduction of the fracture energy (a correlated reduction in the maximum displacement and in the maximum load before failure) and a change in the fracture mode from ductile to brittle as defined in fractography analysis. The force-crosshead displacement curves obtained during the loading tests in sodium and in argon can be directly compared. A typical case is illustrated by the curves shown in Fig. 4 for $316 \mathrm{~L}(\mathrm{~N})$ stressed in sodium and in argon at a cross head displacement rate of $1.66 \times 10^{-6} \mathrm{~m} \mathrm{~s}^{-1}$ at $673 \mathrm{~K}$. The fracture energy is calculated by integrating the area below the loaddisplacement curve that reflects the work spent to break the specimens in two. The extent of the fracture energy reduction is indicated by the relative fracture energy $\mathrm{R}_{\mathrm{E}}$ (calculated using the ratio of the fracture energy in sodium $\mathrm{J}_{\mathrm{Na}}$ and the reference fracture energy in argon $\mathrm{J}_{\mathrm{Ar}}$ ). A summary of the mechanical tests conditions and the results of the analysis in terms of fracture mode, relative fracture energy is given in Table 2. For the example given in Fig. 4, the fracture energy of the $316 \mathrm{~L}(\mathrm{~N})$ is reduced by about $19 \%( \pm 5 \%)$ in sodium at $673 \mathrm{~K}$. It can also be observed on the mechanical curves that crack initiation occurs only after a significant amount of plastic deformation. This behavior is typical of LME where a threshold stress is required to trigger crack initiation generally followed by sub-critical brittle crack propagation. The evolution of the relative fracture energy as a function of temperature is plotted in Fig. 5 for the three stainless steels (with an estimated systematic error of $5 \%$ coming from uncertainty in the notch depth). At the lowest investigated temperature, no effect is observed. However, a reduction in resistance to failure for specimens tested in liquid sodium is observed starting from 573,623 and $673 \mathrm{~K}$ respectively for $304 \mathrm{~L}, 316 \mathrm{~L}(\mathrm{~N})$ and $316 \mathrm{~L}$ grades.

Scanning Electron Microscopy (SEM) observations were performed to characterize the fracture mode for each specimen. Examples of fracture surface appearance of samples tested in sodium and specimens tested in argon at $673 \mathrm{~K}$ are shown in Figs. 6-8. The decrease in the fracture energy in liquid sodium from $573 \mathrm{~K}, 623 \mathrm{~K}$ and $673 \mathrm{~K}$ for $304 \mathrm{~L}, 316 \mathrm{~L}(\mathrm{~N})$ and $316 \mathrm{~L}$ respectively was correlated with a change in the fracture mode. Indeed, the fracture surface of these specimens appears essentially composed of two parts: a brittle outer ring of approximately $100-200 \mu \mathrm{m}$ width near the

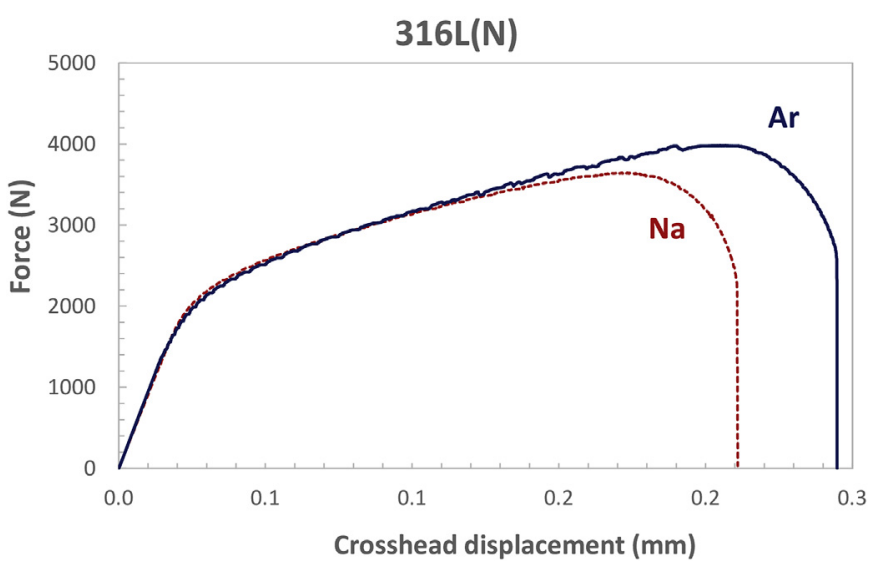

Fig. 4. Load-crosshead displacement curves at $673 \mathrm{~K}$ at a displacement rate of $1.66 \times 10^{-6} \mathrm{~m} \mathrm{~s}^{-1}$ in sodium and in argon of $316 \mathrm{~L}(\mathrm{~N})$. 
Table 2

Fracture mode, relative fracture energy and LME sensitivity of $304 \mathrm{~L}, 316 \mathrm{~L}$ and $316 \mathrm{~L}(\mathrm{~N})$ as a function of the test parameters.

\begin{tabular}{|c|c|c|c|c|c|c|c|c|c|c|c|c|}
\hline Element & C & $\mathrm{Cr}$ & Mn & $\mathrm{P}$ & $\mathrm{Ni}$ & $\mathrm{Si}$ & $S$ & Co & $\mathrm{Cu}$ & $\mathrm{N}$ & Mo & $\mathrm{Fe}$ \\
\hline $304 \mathrm{~L}$ & 0.015 & 18.6 & 1.48 & 0.023 & 9.0 & 0.42 & 0.001 & 0.10 & - & - & - & Balance \\
\hline $316 \mathrm{~L}$ & 0.016 & 16.8 & 1.8 & 0.026 & 10.2 & 0.64 & 0.030 & - & 0.23 & 0.025 & 2.1 & Balance \\
\hline $316 \mathrm{~L}(\mathrm{~N})$ & 0.012 & 17.9 & 1.72 & 0.034 & 12.1 & 0.45 & 0.025 & 0.0008 & 0.00025 & 0.07 & 2.35 & Balance \\
\hline
\end{tabular}

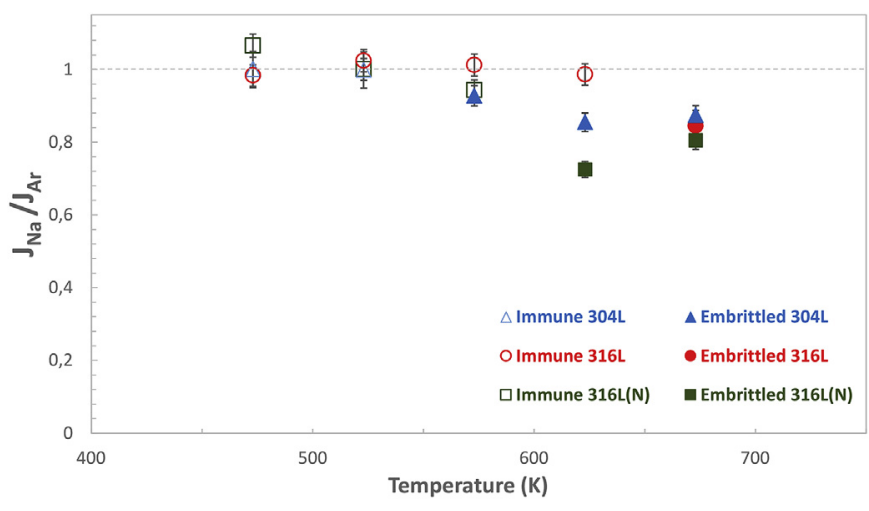

Fig. 5. Relative fracture energy as a function of the temperature for the 3 grades of Stainless Steels.

notch followed by a ductile part in the center via the void growth and coalescence fracture mechanism (Figs. 6-8 (b)). Due to the strain concentration at the notch, brittle cracking onset is due to occur in the outer layer from the notch. Thus, the brittle surface is caused by liquid sodium induced fracture and the brittle crack propagates sub-critically inward in competition with the ductile fracture mode that proceeds at the center of the sample. In the brittle area, evidence of inter-granular fracture (decohesion between grain boundaries of the initial microstructure) is observed
(Fig. $6 \mathrm{~d}$ for example). Moreover, the brittle area contains varying fractions of transgranular fractures (transgranular is understood here relative to the initial microstructure) (Fig. 7c and $\mathrm{d}$ for example). Furthermore, cleavage like fracture can be recognized by the faceted nature of the fracture surface as observed in Fig. 8c, this kind of fracture absorbs very little energy. However, it represents a low fraction of the brittle surface and as such should contribute weakly to the loss of elongation.

The fracture mode of all the specimens tested under argon environment (reference tests) is ductile (the entirety of the fracture surface is ductile with no brittle crown as illustrated in Figs. 6-8(e,f)). Besides the voids, coarse slip bands, reflecting a strong tendency to strain localization are formed guiding the ductile crack path.

Additional mechanical tests were conducted to evaluate a possible effect of the corrosion layer induced by pre-wetting in liquid sodium on the LME. Tensile tests were carried out at $473 \mathrm{~K}$ on reference samples (pre-exposed to sodium at $823 \mathrm{~K}$ for $250 \mathrm{~h}$ and tested after the removal of sodium residue) and the as-received specimens (no pre-exposure in sodium). No loss of the elongation to failure was observed with the corroded notch state which indicates that corrosion during pre-wetting has no contribution on the mechanical properties of the austenitic steels. Thus, any reported reduction in the mechanical properties is solely the result of the dynamic interaction between the liquid sodium and the steel.
$\mathrm{Na}$
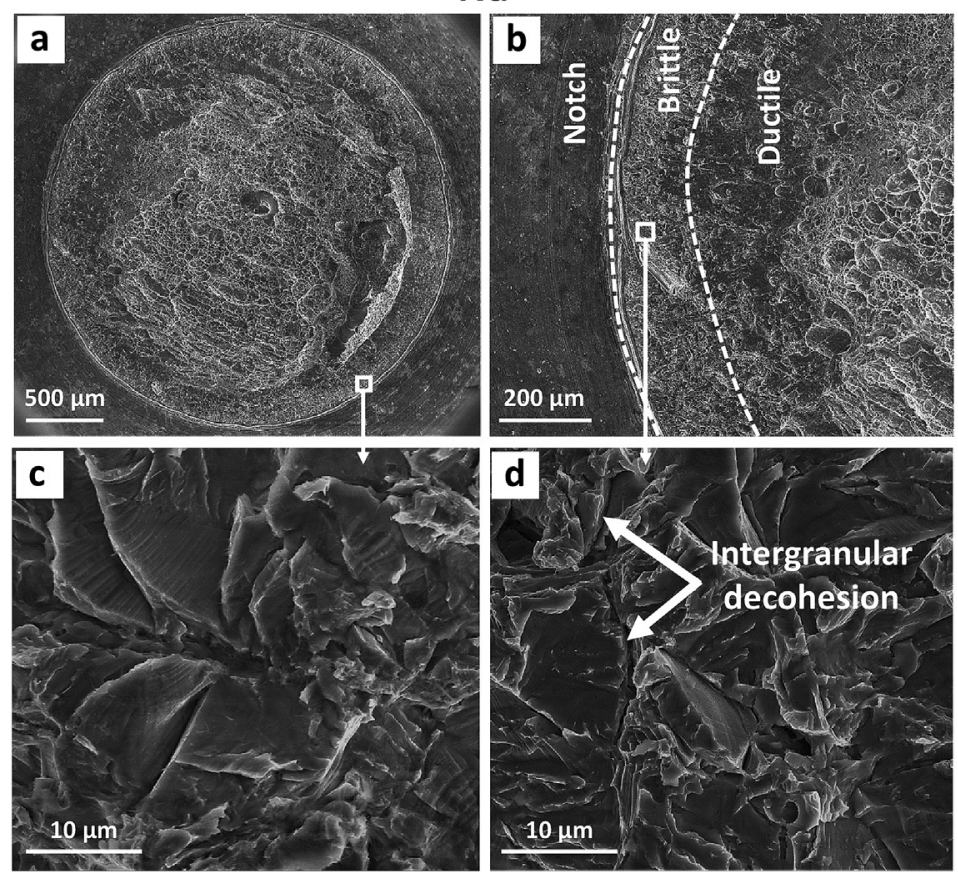

Ar
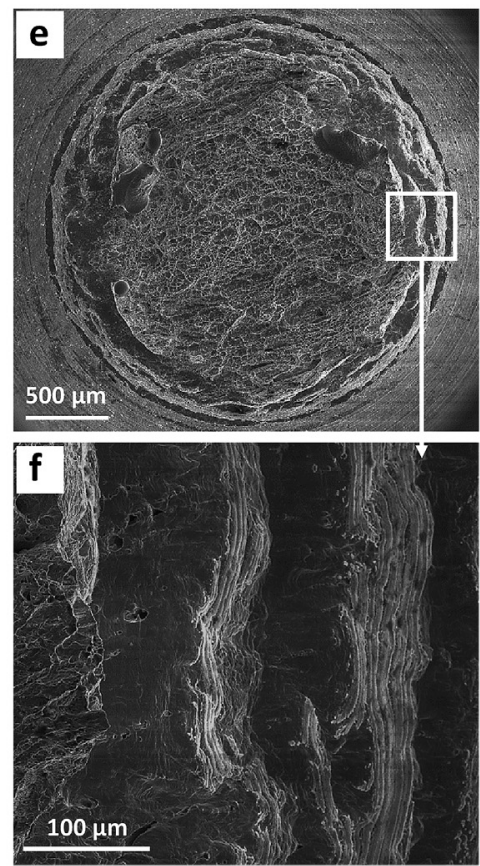

Fig. 6. Fracture analysis after tensile test $(\mathrm{a}-\mathrm{d})$ in sodium and $(\mathrm{e}-\mathrm{f})$ in $\operatorname{argon}$ at $673 \mathrm{~K}$ for $304 \mathrm{~L}$. 
$\mathrm{Na}$
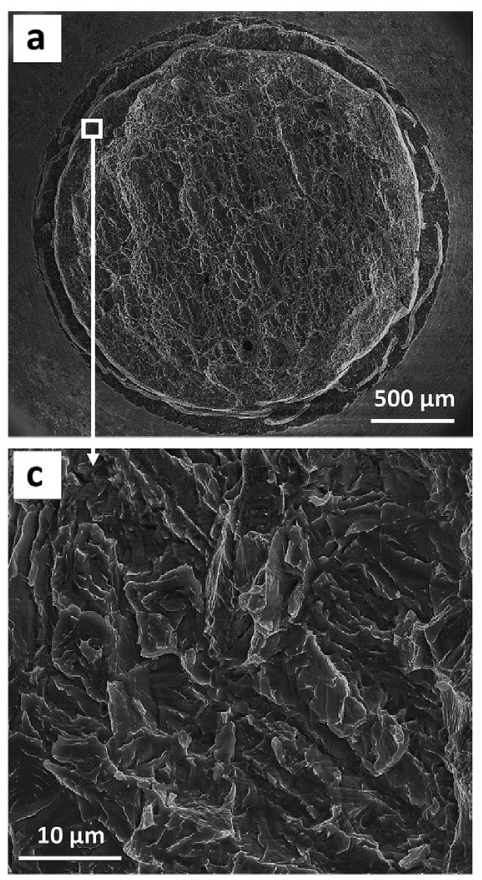
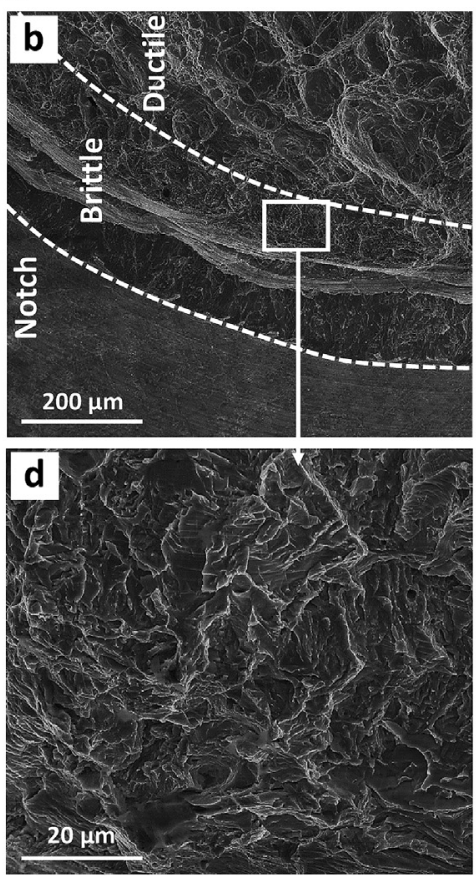

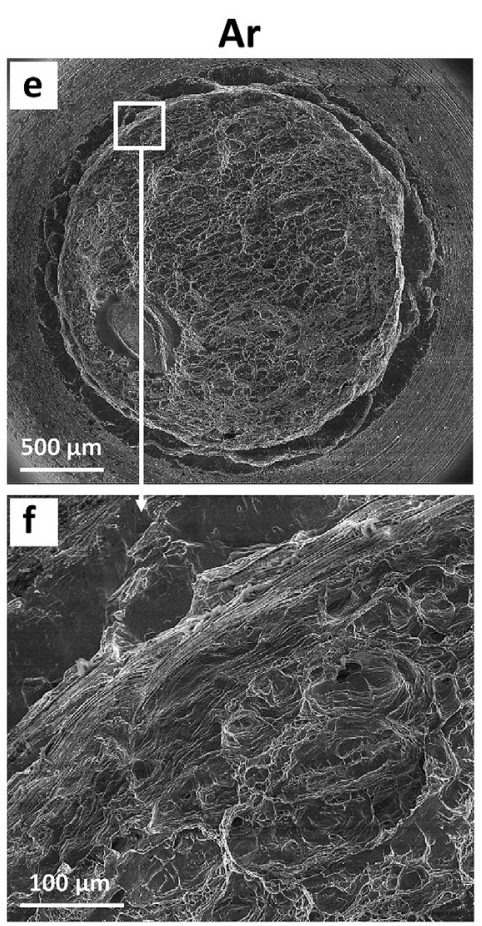

Fig. 7. Fracture analysis after tensile test $(\mathrm{a}-\mathrm{d})$ in sodium and $(\mathrm{e}-\mathrm{f})$ in $\arg$ on at $673 \mathrm{~K}$ for $316 \mathrm{~L}$.

\section{$\mathrm{Na}$}
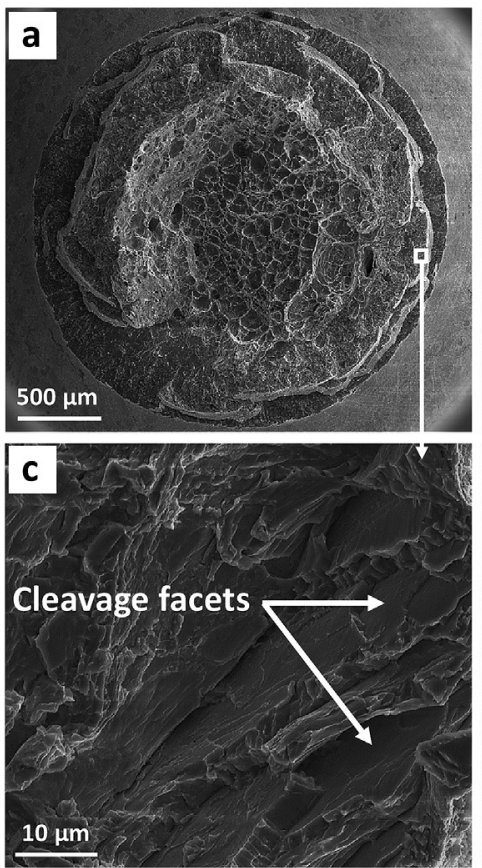
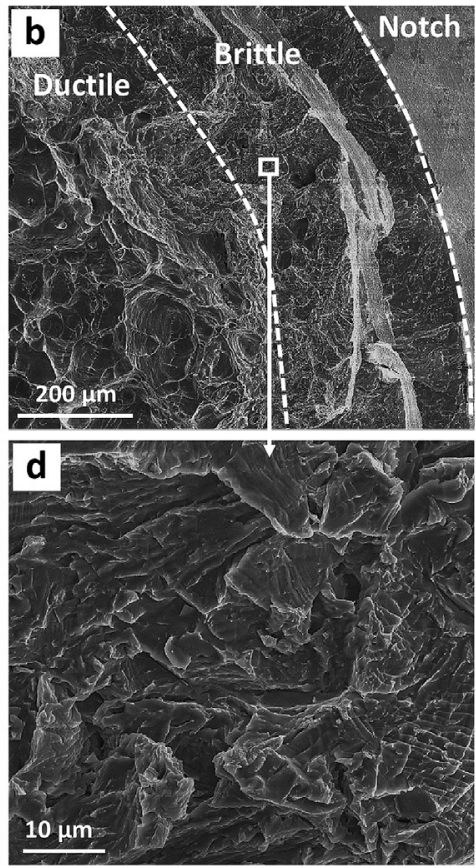

$\mathrm{Ar}$
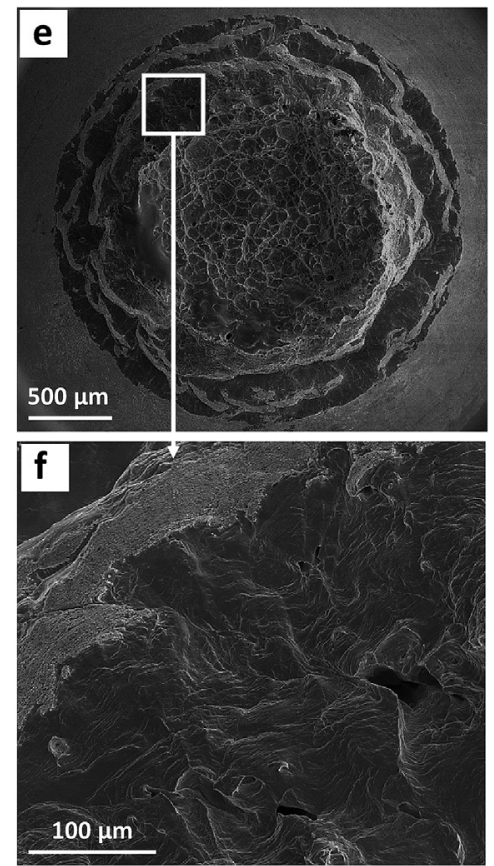

Fig. 8. Fracture analysis after tensile test $(\mathrm{a}-\mathrm{d})$ in sodium and (e-f) in argon at $673 \mathrm{~K}$ for $316 \mathrm{~L}(\mathrm{~N})$.

\section{Discussion}

In the literature, only few studies were dedicated to the LME susceptibility of austenitic steels in liquid sodium. This is probably because as mentioned earlier, austenitic steels are supposed to be insensitive to LME unlike ferritic or martensitic steels or even have better creep damage resistance than in air in the case of sodium environment [3]. Our results, carried out with pre-wetting conditions to enable reproducible crack initiation, indicate clearly that after large plastic deformation, the fracture behavior of the three tested austenitic steels shows typical LME features. This includes a loss of crack propagation resistance and a change in rupture surfaces with evidence of brittle fracture.

Serre et al. [13] reported that, in their conditions, liquid metal 
embrittlement has not to be considered for the $316 \mathrm{~L}(\mathrm{~N})$ austenitic steel in the temperature range [473-823 K]. These authors observed a slight reduction in the mechanical properties for the specimens tested by small punch test in liquid sodium but the fracture mode remains fully ductile in their conditions. They concluded that the $316 \mathrm{~L}(\mathrm{~N})$ is prone to liquid metal accelerating damage (LMAD) but not Liquid Metal Embrittlement (LME). Still, this study may have missed the range or the conditions where LME can be maximum, even though a broad range of mechanical test parameters such as temperature and strain rate was investigated [17]. Our study shows that the $304 \mathrm{~L}$, the $316 \mathrm{~L}$ and, contrary to prior results of reference [13], the $316 \mathrm{~L}(\mathrm{~N})$ austenitic steels have a lower crack propagation resistance in oxygenated liquid sodium. This difference in LME response for $316 \mathrm{~L}(\mathrm{~N})$ could be attributed to the higher triaxiality of the axisymmetric notched geometry compared with the SPT test used by Serre et al. [13]. More critically, the absence of LME could also be explained by an incomplete or absence of wetting since it is possible that an insufficient wetting was reached before SPT tests. Hemery et al. [5] had illustrated the influence of the exposure duration on the LME susceptibility and found that an increase in the exposure duration enhances the wettability of T91 martensitic steel by liquid sodium and that LME was coincident with the onset of good wetting of the specimens.

A LME case in oxygenated liquid sodium has already been reported on $304 \mathrm{~L}$ austenitic steel in a previous study using the same severe loading geometry [11]. Hemery et al. observed 5-25\% reduction in the fracture energy of $304 \mathrm{~L}$ steel associated with a change in fracture mode from ductile to brittle in the temperature range between 573 and $673 \mathrm{~K}$. It was later on demonstrated that the fracture is typically an interfacial fracture in an evolving microstructure induced by plastic deformation where the $\gamma$ to $\alpha^{\prime}$ martensitic transform plays a critical role [12]. The dioxygen and humidity of the gas phase were kept relatively low during mechanical test ( $<100 \mathrm{ppm}$ ). Because non-metallic impurities (mainly hydrogen and sodium hydroxide) in liquid sodium might be susceptible to affect the LME phenomenon, these impurities concentrations could still be relatively high compared to those considered adequate in the context of an operating loop. Here we qualitatively reproduced these prior results but with a lower level of impurities in the cover gas $(<1 \mathrm{ppm})$ due to the addition of an online purification system. This may disregard a potential role of impurities at the origin of this fracture case but one might still want to review their potential role in the observed fracture mode change.

A possible scenario at the origin of the embrittlement that is observed is the influence of sodium hydroxide $(\mathrm{NaOH})$. According to corrosion tests under static stress of Berge et al. [10] on an 18-10 austenitic steel at $823 \mathrm{~K}$ in sodium polluted with hydroxide sodium, the fracture mode was intergranular which is typical of stress corrosion cracking in these conditions. At the same time, no such behavior was observed at $623 \mathrm{~K}$. This study also reports that sodium hydroxide remains stable in liquid sodium only when the dihydrogen partial pressure is significant ( 7000 Pa at $623 \mathrm{~K})$. Otherwise it will decompose into $\mathrm{NaH}$ and $\mathrm{Na}_{2} \mathrm{O}$. The level of ambient humidity impinging on the sodium free level during tensile testing is clearly not enough to bring enough sodium hydroxide formation. The sodium free level surface remains visually shiny during the test whereas oversaturation would manifest itself by a white deposit floating on liquid sodium. In addition, the characteristic crack propagation rate at $823 \mathrm{~K}$ was measured to be of the order of $2.10^{-4} \mu \mathrm{m} \mathrm{s}^{-1}$ for $5 \mathrm{w} \%$ of sodium hydroxide (calculated from Ref. [10]). In our experiments, the characteristic crack propagation rate goes from 0.2 to $0.5 \mu \mathrm{m} \mathrm{s}^{-1}$ (same order of magnitude than reported in Ref. [11]). This crack speed is a thousand time faster than that measured by Berge et al. [10]. The brittle crack propagation that we observe in this work is therefore significantly faster while the purity conditions in our tests prevent a $\mathrm{NaOH}$ contamination of the magnitude encountered in the Berge et al. study [10].

The fracture surfaces are also totally different since a clear intergranular cracking at austenitic grain boundaries was observed, a clear deviance from the interfacial fracture mode on plastically formed interfaces observed for $304 \mathrm{~L}$ for instance in prior work [12]. Thus, for these two reasons, a sodium hydroxide stress corrosion cracking mechanism is deemed extremely unlikely in our case.

Another possible impurity of concern is hydrogen which is known to induce hydrogen embrittlement phenomenon. The only possible source of hydrogen in our setup is the decomposition below saturation into dissolved oxygen and hydrogen of sodium hydroxide formed with the water vapor influx. The contamination flux from the residual humidity supply at the sodium free level can be estimated using the collision rate from the gas kinetic theory [18]. Given that the water vapor content is constant during the test (equals to $1 \mathrm{ppm}$ ) then the free surface of liquid sodium wetting the notch $\left(\sim 8.7 \mathrm{~mm}^{2}\right)$ is collided by $310^{-5} \mathrm{~mol}$ of water molecules per hour. In our calculation, the geometrically constrained weight of the liquid metal droplet taken into account is estimated to lie between $0.01 \mathrm{~g}$ and $0.1 \mathrm{~g}$. If one supposes that every molecule reacts with sodium (a conservative hypothesis), this leads to an increase in the hydrogen content from 0.3 to 6 wppm $(433 \mathrm{~K}-533 \mathrm{~K}$ in saturation). According to these assessments, considering that the average durations of the tests are $1 \mathrm{~h}, 0.5 \mathrm{~h}$ and $0.3 \mathrm{~h}$ at respectively $573 \mathrm{~K}, 623$ and $673 \mathrm{~K}$, the uptake of hydrogen remains therefore limited or negligible. Moreover, hydrogen embrittlement is known to occur only below room temperature with austenitic steels [19]. The reduction in mechanical properties observed in this study is more obvious at $623 \mathrm{~K}$, i.e. more than $300 \mathrm{~K}$ above the temperature at which the known weakening effects of hydrogen solutes disappear with austenitic steels.

Oxygen, the other important soluble specie in liquid sodium, was deliberately added in our pre-wetting procedure. Our estimate of the influx of oxygen due to residual humidity (assuming sodium hydroxide decomposition) leads to an increase in the dissolved oxygen content from 5 to $50 \mathrm{wppm}$ during the course of the mechanical loading phase (these concentrations are the saturation levels at 620 and $634 \mathrm{~K}$ ). The increase in oxygen due to contamination is small and does not drastically change the oxygen concentration during the test duration.

To study the effect of dissolved oxygen in liquid sodium on crack propagation, James and Knecht [20] carried out fatigue tests at $700 \mathrm{~K}$ on 304 austenitic steel in liquid sodium. They found that an increase in the dissolved oxygen in liquid sodium concentration from $(1-3 \mathrm{wppm})$ to $(20-40 \mathrm{wppm})$ did not affect the crack propagation rate in stage III. In another study [21], it was also shown that, while varying the oxygen content of sodium from 0.7 to $14 \mathrm{wppm}$, the intergranular crack growth had only a slight increase and so was deemed largely independent upon the dissolved oxygen concentration. It should therefore be anticipated that the oxygenated condition is no more detrimental than ultrapure sodium.

One could advocate that the results of the present work are the manifestation of the internal oxidation along grain boundaries mechanism for stress corrosion cracking (SCC) [22]. The dissolved oxygen available next to the crack tip adsorbs and diffuses along the grain boundary, preceding then ultimately causing a brittle crack propagation. The crack growth rate should then be within the same order of magnitude than the oxygen diffusion distance $\left(<\mathrm{x}^{2}\right\rangle=\mathrm{Dt}$, $\mathrm{D}$ being the internal oxidation diffusion coefficient and $\mathrm{t}$ the time interval [18]).

These are typically evaluated from high temperature grain boundary oxygen diffusion measurements and then extrapolated in the low temperature range. However, for nickel based alloys the intergranular oxygen diffusion rates, as reviewed by Staehle et al. 
[23], cannot explain the observed SCC crack growth rate $\left(\sim 10^{-5} \mu \mathrm{m} \mathrm{s}^{-1}\right)$ in the low temperature range $(550-630 \mathrm{~K})$ because diffusion should be increased by some 5 orders of magnitude. To account for such gap, accelerated diffusion under stress have been proposed with no consensus on such mechanism [23,24]. For the case of steels, Moazhong et al. provided an estimate for the diffusion coefficient of oxygen in low alloyed steels from high temperature measurements in the $\gamma$ phase domain (1123-1389 K) [25]. Extrapolated back at $673 \mathrm{~K}$, the diffusion distance reads 0.6 $10^{-4} \mu \mathrm{m} \mathrm{s}^{-1}$ that is, similarly to these types of estimates for nickel based alloys, orders of magnitude lower than the one observed in our study $\left(0.2-0.5 \mu \mathrm{m} \mathrm{s}^{-1}\right)$. Given the lack of accurate and well understood oxygen diffusion data in a plastically deformed microstructure under stress, it remains to be demonstrated that such mechanism is at work in our case to explain the observed crack propagation rates. The brittle fracture mode observed during the crack propagation phase should rather be attributed here to the presence of liquid sodium at the crack tip and we conjecture that the presence of dissolved oxygen is probably a minor effect, or even unimportant, in the brittle cracking.

Finally, after looking at the potential role of several impurities ( $\mathrm{NaOH}$, dissolved $\mathrm{H}$ and dissolved $\mathrm{O}$ ), we conclude that it appears difficult to explain the results of the present work with an impurity effect.

Recent investigations of the fine-scale microstructural relationship of the LME crack propagation point out at the importance of new interfaces created during plastic deformation [12,15]. They were shown to lead to a preferential crack path when fracture is triggered by liquid sodium. We stress out the intrinsic complexity of plasticity in the case of austenitic steels such as $304 \mathrm{~L}$ or $316 \mathrm{~L}$ where martensitic transformations $\left(\gamma-\varepsilon\right.$ and $\left.\gamma-\alpha^{\prime}\right)$, twinning or nano-twinning and dynamical strain aging (DSA) occur at varying temperatures and strain rates $[26,27]$. The question raised by the present work is to understand if the observed LME behavior fits within the interfacial cracking realm for all the investigated steels. So far only the $304 \mathrm{~L}$ steel has been investigated and the fracture modes characterization remains to be investigated with the $316 \mathrm{~L}$ and $316 \mathrm{~L}(\mathrm{~N})$ steels. We notice the seemingly coincidence of the embrittling temperature range (573-673 K) with the temperature domain where DSA is known to occur in austenitic steels [26]. Further observations at nanoscales are left for future work to reach a quantitative understanding of these sodium induced LME cases.

\section{Conclusion}

An experimental device has been set up to investigate the susceptibility to liquid sodium embrittlement during tensile loading on notched axisymmetric specimens at temperatures ranging from $473 \mathrm{~K}$ up to $673 \mathrm{~K}$ with high purity Ar cover gas. The results show that the crack propagation resistance of $304 \mathrm{~L}, 316 \mathrm{~L}(\mathrm{~N})$ and $316 \mathrm{~L}$ stainless steels is reduced in oxygenated liquid sodium (200 wppm) starting from $573 \mathrm{~K}, 623 \mathrm{~K}$ and $673 \mathrm{~K}$ respectively provided that good wetting is achieved by prior short-term exposure in oxygenated sodium. Given the low impurities gas concentration in the newly developed experimental device and the subsequent analysis of the potential role of main sodium impurities $(\mathrm{NaOH}$, dissolved $\mathrm{H}$ and dissolved $\mathrm{O}$ ), the observed brittle fracture mode is therefore most likely due to the presence of liquid sodium at the crack tip. An effect of non-metallic sodium impurities is deemed unlikely. We note that there is quite a large threshold plastic deformation with the as-received materials before LME sets in that is similar to previous results with martensitic steels [5]. This concurs to the mild reduction in crack propagation resistance.

\section{Acknowledgements}

Financial support for this work by the CEA-ASTRID project is gratefully acknowledged, as well as fruitful discussions with D. Féron (CEA-Saclay), V. Grabon (AREVA NP - Lyon) and M. BlatYrieix (EDF R\&D - Les Renardières).

\section{Appendix A. Supplementary data}

Supplementary data related to this article can be found at https://doi.org/10.1016/j.jnucmat.2018.04.036.

\section{References}

[1] N.P. Bhat, H.U. Borgstedt, Corrosion behaviour of structural materials in sodium influenced by formation of ternary oxides, Mater. Corros. 39 (1988) $115-123$.

[2] C. Fazio, F. Balbaud, Corrosion phenomena induced by liquid metals in Generation IV reactors, in: Pascal Yvon (Ed.), Structural Materials for Generation IV Nuclear Reactors, Woodhead Publishing, 2017, pp. 23-74.

[3] O.K. Chopra, Effects of sodium and lithium environments on mechanical properties of ferrous alloys, J. Nucl. Mater. 115 (1983) 223-238.

[4] J.P. Hilditch, J.R. Hurley, P. Skeldon, D.R. Tice, The liquid metal embrittlement of iron and ferritic steels in sodium, Corrosion Sci. 37 (1995) 445-454.

[5] S. Hémery, T. Auger, J.L. Courouau, F. Balbaud-Célérier, Effect of oxygen on liquid sodium embrittlement of T91 martensitic steel, Corrosion Sci. 76 (2013) $441-452$.

[6] K. Natesan, M. Li, O.K. Chopra, S. Majumdar, Sodium effects on mechanical performance and consideration in high temperature structural design for advanced reactors, J. Nucl. Mater. 392 (2009) 243-248.

[7] T. Furukawa, S. Kato, E. Yoshida, Compatibility of FBR materials with sodium, J. Nucl. Mater. 392 (2009) 249-254.

[8] H.U. Borgstedt, G. Drechsler, G. Frees, H.S. IChatak, Z. Peric, B. Seith, The in fluence of liquid sodium on the fracture of stainless steel, Int. J. Fract. 32 (1986) 23-28.

[9] H.U. Borgstedt, H. Huthmann, Influence of sodium on the creep-rupture behaviour of Type 304 stainless steel, J. Nucl. Mater. 183 (1991) 127-136.

[10] Ph Berge, C. Oberlin, P. Saint-Paul, M. Zbinden, Corrosion des matériaux pour générateurs de vapeur des réacteurs à neutrons rapides, refroidis au sodium, dans le sodium pollué par de la soude, J. Nucl. Mater. 66 (1977) 65-78.

[11] S. Hémery, T. Auger, J.L. Courouau, F. Balbaud-Célérier, Liquid metal embrittlement of an austenitic stainless steel in liquid sodium, Corrosion Sci. 83 (2014) $1-5$.

[12] B. Barkia, T. Auger, J.L. Courouau, J. Bourgon, Multiscale investigation of crack path and microstructural changes during liquid metal embrittlement of 304L austenitic steel in liquid sodium, Corrosion Sci. 127 (2017) 213-221.

[13] I. Proriol-Serre, O. Hamdane, J.B. Vogt, Comparative study of the behavior of different highly alloyed steels in liquid sodium, Nucl. Eng. Des. 320 (2017) $17-27$.

[14] M. Barlow, P.J. Planting, Wetting of metal surfaces by liquid alkali metals, Z. Metallkd. 60 (1969) 719-722.

[15] B. Barkia, T. Auger, J.L. Courouau, J. Bourgon, Wetting by liquid sodium and fracture path analysis of sodium induced embrittlement of 304L stainless steel, J. Mater. Res. 33 (2018) 121-129.

[16] J.L. Courouau, F. Balbaud-Célérier, V. Lorentz, T. Dufrenoy, Corrosion by liquid sodium of materials for sodium fast reactors: the CORRONa testing device, in: the Société Française d'Energie Nucléaire (Ed.), International Congress on Advances in Nuclear Power Plants 2011, 2011, p. 11152. Paris, France, https:// inis.iaea.org/search/search.aspx?orig_q=RN:44092769.

[17] P.J.L. Fernandes, D.R.H. Jones, Specificity in liquid metal induced embrittlement, Eng. Fail. Anal. 3 (1996) 299-302.

[18] G. Hultquist, C. Leygraf, The initiation of selective oxidation of a ferritic stainless steel at low temperatures and oxygen pressures, Corrosion Sci. 22 (1982) 331-346.

[19] G. Han, J. He, S. Fukuyama, K. Yokogawa, Effect of strain-induced martensite on hydrogen environment embrittlement of sensitized austenitic stainless steels at low temperatures, Acta Mater. 46 (1998) 4559-4570.

[20] L.A. James, R.L. Knecht, Fatigue-crack propagation behavior of type 304 stainless steel in a liquid sodium environment, Metall. Trans. 6A (1975) $109-116$.

[21] H. Abe, S. Shimoyashiki, Time dependent crack growth of type 304 stainless steel in elevated temperature sodium, Eng. Fract. Mech. 26 (1987) 657-667.

[22] V.S. Raja, T. Shoji, Stress Corrosion Cracking: Theory and Practice, first ed, Woodhead publishing limited, Cambridge, 2011.

[23] R.W. Staehle, Z. Fang, Comments on a proposed mechanism of interna oxidation for alloy 600 as applied to low potential SCC, in: F.P. Ford, S.M. Bruemmer, G.S. Was (Eds.), Proc. 9th International Symposium on Environmental Degradation of Material in Nuclear Power Systems - Water Reactors, The minerals, Metals \& materials society (TMS), 1999, p. 69.

[24] P.M. Scott, An overview of internal oxidation as a possible explanation of 
intergranular stress corrosion cracking of alloy 600 in PWRs, in: F.P. Ford S.M. Bruemmer, G.S. Was (Eds.), Proc. 9th International Symposium on Environmental Degradation of Material in Nuclear Power Systems - Water Reactors, The minerals, Metals \& materials society (TMS), 1999, pp. 3-13.

[25] Y. Maozhong, L. Jiansheng, A study on diffusion coefficient of oxygen in steel, Chin. J. Mech. Eng. 3 (1990) 194.
[26] G. Meric de Bellefon, J.C. van Duysen, Tailoring plasticity of austenitic stainless steels for nuclear applications: review of mechanisms controlling plasticity of austenitic steels below $400^{\circ} \mathrm{C}$, J. Nucl. Mater. 475 (2016) 168-191.

[27] Y.F. Shen, X.X. Li, X. Sun, Y.D. Wang, L. Zuo, Twinning and martensite in a 304 austenitic stainless steel, Mater. Sci. Eng. A 552 (2012) 514-522. 